\title{
Engineered repressors are potent inhibitors of androgen receptor activity
}

\author{
Greg N. Brooke ${ }^{1,2}$, Sue M. Powell ${ }^{1}$, Derek N. Lavery ${ }^{1}$, Jonathan Waxman ${ }^{1}$, Laki \\ Buluwela $^{1}$, Simak Ali ${ }^{1}$ and Charlotte L. Bevan ${ }^{1}$ \\ ${ }^{1}$ Department of Surgery and Cancer, Imperial Centre for Translational and Experimental Medicine, Imperial College London, \\ W12 ONN, UK. \\ ${ }^{2}$ School of Biological Sciences, University of Essex, Wivenhoe Park, Colchester CO4 3SQ, UK. \\ Correspondence: \\ Charlotte Bevan, e-mail: charlotte.bevan@imperial.ac.uk \\ Keywords: Androgen receptor, Prostate cancer, Anti-androgen, Castrate resistant prostate cancer
}

Received: September 05, $2013 \quad$ Accepted: November 20, $2013 \quad$ Published: January 21, 2014

\begin{abstract}
Prostate cancer growth is dependent upon the Androgen Receptor (AR) pathway, hence therapies for this disease often target this signalling axis. Such therapies are successful in the majority of patients but invariably fail after a median of 2 years and tumours progress to a castrate resistant stage (CRPC). Much evidence exists to suggest that the AR remains key to CRPC growth and hence remains a valid therapeutic target. Here we describe a novel method to inhibit AR activity, consisting of an interaction motif, that binds to the AR ligand-binding domain, fused to repression domains. These 'engineered repressors' are potent inhibitors of AR activity and prostate cancer cell growth and importantly inhibit the AR under circumstances in which conventional therapies would be predicted to fail, such as AR mutation and altered cofactor levels.
\end{abstract}

\section{INTRODUCTION}

The Androgen Receptor (AR) is a ligand-dependent transcription factor and like other members of the Nuclear Receptor family, has a modular structure consisting of the N-terminal domain, the central DNA-binding domain and the C-terminal ligand-binding domain [1]. The receptor contains two activation functions (AF), the predominant AF-1 in the N-terminus and the weaker ligand dependent AF-2 in the ligand binding domain (LBD) [2]. In the absence of ligand the receptor is localised in the cytoplasm, associated with a heat shock protein complex that holds the receptor in a ligand binding competent conformation. Upon ligand binding the receptor undergoes a conformational change, which promotes nuclear localisation, dimerization, recruitment of accessory proteins and an intramolecular $\mathrm{N}$-/C-terminal interaction [3]. The $\mathrm{N}-/ \mathrm{C}$-terminal interaction is important in reducing ligand off rate and increasing receptor stability [4]. The importance of this interaction in AR transcriptional activity, however, appears to be promoter specific $[5,6]$.

Coactivators are proteins that bind to and enhance the activity of transcription factors while not directly binding DNA themselves. Steroid receptor coactivators, such as the p160 family, often interact with the AF-2 surface of agonist-bound nuclear receptors, via an $\alpha$-helical LxxLL motif $[7,8]$. However, the AR differs from other steroid receptors in that it has greater affinity for phenylalanine rich motifs, such as the FQNLF motif found in the N-terminus of the AR that mediates the N-/Cterminal interaction, and those found in coactivators such as ARA70 [9-11]. This difference in interaction motif preference between steroid receptors is a result of a deeper coactivator interaction groove on the surface of the active (holo) form of the AR LBD, which can accommodate the bulkier phenylalanine residues $[10,12]$. Conversely AR, like other steroid receptors, can interact with corepressor proteins (such as $\mathrm{NCoR}$ ) in the presence of antagonists, which promote a different LBD conformation [13-15]. Corepressors bind to the LBD of nuclear receptors at a distinct region that nevertheless overlaps with the coactivator-interacting region and subsequently inhibit transcription of target genes [13, 16].

Prostate cancer growth is almost always dependent upon the androgen-signalling axis and as a result, 
androgen deprivation therapy is a common treatment option for this disease. This involves one or both of chemical castration to ablate circulating androgens and antiandrogens - steroidal or non-steroidal ligands that bind to the AR LBD but do not promote subsequent target gene activation, either due to simple competition, by preventing receptor dimerization and/or nuclear translocation and DNA-binding, by promoting formation of a repressive complex at the androgen response element (ARE), or a mixture of mechanisms $[15,17]$. Although antiandrogens are initially successful in the majority of patients, relapse is inevitable and the tumours progress to a "castrate resistant" stage (CRPC), for which few therapeutic options exist. Much evidence exists to suggest that the AR is still driving growth, even in the androgen-depleted environment, including frequent AR amplification and mutation, as well as alterations in cofactor levels and activities [18]. The AR therefore remains a valid target for CRPC and novel methods to inhibit the AR are required. Ideally such therapies would be active even in circumstances where current therapies would be predicted to fail (e.g. mutations of the AR resulting in broadened ligand preference and promiscuous activation [11]).

Due to the limited efficacy of current antiandrogens, novel methods to inhibit AR signalling are being devised that directly target different regions of the AR. Zhang et al., for example, demonstrated that ectopic expression of a decoy androgen response element was successful at reducing AR activity [19]. Other studies demonstrated that targeting either the AF-1 or AF-2 of the AR using peptides, can successfully inhibit AR activity [20-22]. These consist of specific AR-binding motifs, which subsequently block crucial interactions such as the $\mathrm{N}$-/C-terminal interaction and recruitment of coactivators. Another approach is the engineering of AR-specific corepressors. Reeb et al. performed a yeast 2-hybrid peptide screen against the full-length AR in the presence of the antiandrogen hydroxyflutamide [23]. Fusion of the lead interacting peptide with a silencing domain generated an AR corepressor with receptor specific inhibitory effects.

Here we describe the design and validation of AR engineered repressors that combine the desirable characteristics of coactivators and corepressors, in that they interact with the AR when it is in a holo conformation and block its activity. These consist of an interaction motif containing an FxxLF motif, fused to potent repression domains. Importantly, we demonstrate that these factors are successful in inhibiting the AR in circumstances thought to lead to castrate resistant prostate cancer.

\section{RESULTS}

\section{Engineered repressor design}

Previous studies have demonstrated that peptides designed to target intra- and inter-receptor interactions can successfully inhibit AR activity [20,21]. For example, peptides consisting of an FxxLF $\alpha$-helix, which can bind to AF-2 of the AR, inhibit the N-/C-terminal interaction and reduce AR activity [21]. In an attempt to make a more potent inhibitor of the AR, we fused amino acids 1-54 of the AR, which contains the ${ }^{23} \mathrm{FQNLF}^{27}$ motif known to interact with the AR LBD (termed the interaction motif), to known repression domains from different proteins: MAD (amino acids 7-35 [24]), KOX (amino acids 1-75 [25]) and PLZF (amino acids 1-452 [26]). The resulting constructs are $\mathrm{MAD}_{7-35}-\mathrm{AR}_{1-54}, \mathrm{KOX}_{1-75}-\mathrm{AR}_{1-54}$, $\mathrm{PLZF}_{1-452}-\mathrm{AR}_{1-54}$ (Figure 1a). These repressors should not only sterically disrupt coactivator binding and the $\mathrm{N}-/ \mathrm{C}$ terminal interaction, but also bring a potent repression domain in close proximity to the receptor upon activation by ligand.

\section{The engineered repressors interact with the active Androgen Receptor}

As proof of principle to confirm that the repressors and the AR interact, $\mathrm{MAD}_{7-35}-\mathrm{AR}_{1-54}$ was fused to GFP and co-transfected into COS-1 cells with an AR expression vector. Confocal microscopy demonstrated that $\mathrm{MAD}_{7-35}$ $\mathrm{AR}_{1-54}$ is predominantly nuclear and appears to colocalise with the agonist bound AR (Figure 1b), suggesting that the proteins interact. This interaction was confirmed using co-immunoprecipitation, whereby a GFP antibody (against the $\mathrm{MAD}_{7-35}-\mathrm{AR}_{1-54}$ construct) also pulled-down full-length AR (Figure 1c). Importantly, this interaction was ligand-dependent, as would be expected since the interaction of ${ }^{23} \mathrm{FQNLF}^{27}$ within $\mathrm{AR}_{1-54}$ with the $\mathrm{AR}$ ligand binding domain is dependent upon AF-2 being in an active conformation [27].

\section{The engineered repressors inhibit Androgen Receptor activity}

To investigate the repressive activity of the engineered repressors compared to the interaction motif and repression domains in isolation, each was transfected into COS-1 cells along with an AR expression plasmid and an androgen-responsive luciferase reporter gene. The N-terminal 54 amino acid fragment of AR expressed in isolation reduced AR activity by 34\% (Figure 2a). Repression domains in isolation had no effect on AR activity (Figure 2a, solid lines), but when fused to $\mathrm{AR}_{1-54}$ 
(a)

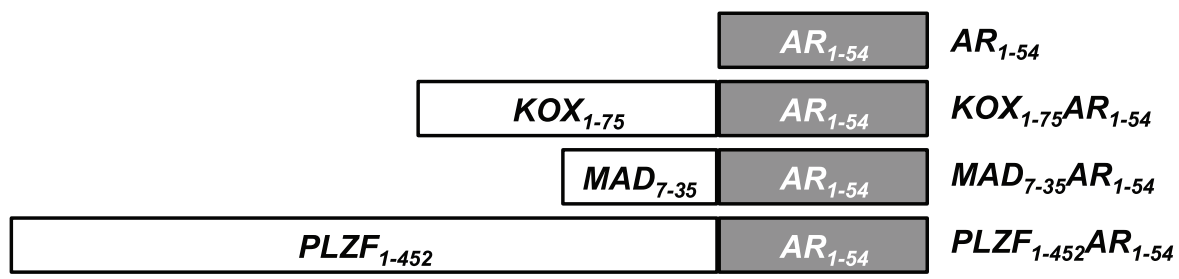

(b)

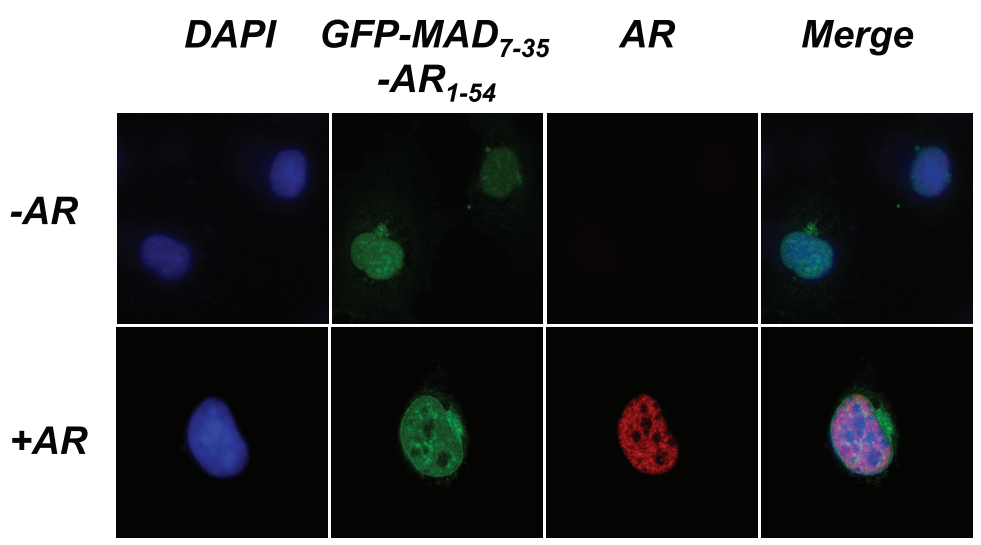

(c)

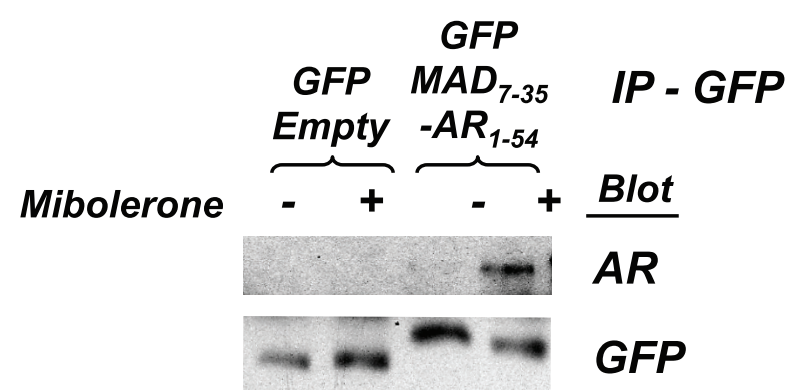

Figure 1: The repressor constructs enter the nucleus and interact with the active androgen receptor. (a) Schematic representation of the engineered repressors (not drawn to scale). (b) COS-1 cells were transfected with the AR and GFP-MAD ${ }_{7-35}-\mathrm{AR}_{1-54}$. Cells were fixed following $2 \mathrm{hrs}$ of treatment with mibolerone. Confocal microscopy was used to visualise the localisation of GFP-MAD ${ }_{7-35}{ }^{-}$ $\mathrm{AR}_{1-54}$ (green) and the full-length AR (stained using ALEXA 594 (red)). Nuclear staining = DAPI (blue). (c) COS-1 cells were transfected with the $\mathrm{AR}$ and and GFP-MAD ${ }_{7-35}-\mathrm{AR}_{1-54}$ or GFP-Empty. Cells were treated \pm mibolerone for $2 \mathrm{hrs}$ and complexes immunoprecipitated with an anti-GFP antibody. Immunoprecipitated complexes were separated using SDS-PAGE and immunoblotted for AR (using an antibody that does not recognise residues 1-54) and GFP.

the resulting fusion constructs had greater inhibitory action than the interaction motif alone: maximal repression for $\mathrm{AR}_{1-54}-\mathrm{KOX}_{1-75}$ was $57 \%$, for $\mathrm{MAD}_{7-35}-\mathrm{AR}_{1-54}$ was $81 \%$ and for $\mathrm{PLZF}_{1-452}-\mathrm{AR}_{1-54}$ was $86 \%$ (Figure $2 \mathrm{a}$, broken lines). To ensure that this effect was not an artefact of cell line used or transiently transfected AR, PC3-WTAR cells (PC3 prostate cancer cell line stably expressing AR [28]) were transfected with a luciferase reporter and the repressors. Similar to the repressive effects demonstrated in the COS-1 cell line, the engineered repressors potently inhibited AR activity in PC3 cells (Figure 2b).

The interaction domain utilised in the engineered repressors contains a phenylalanine rich motif (FQNLF), which should be specific for the AR. To investigate if the 
(a)

Repression domain / interaction motif:
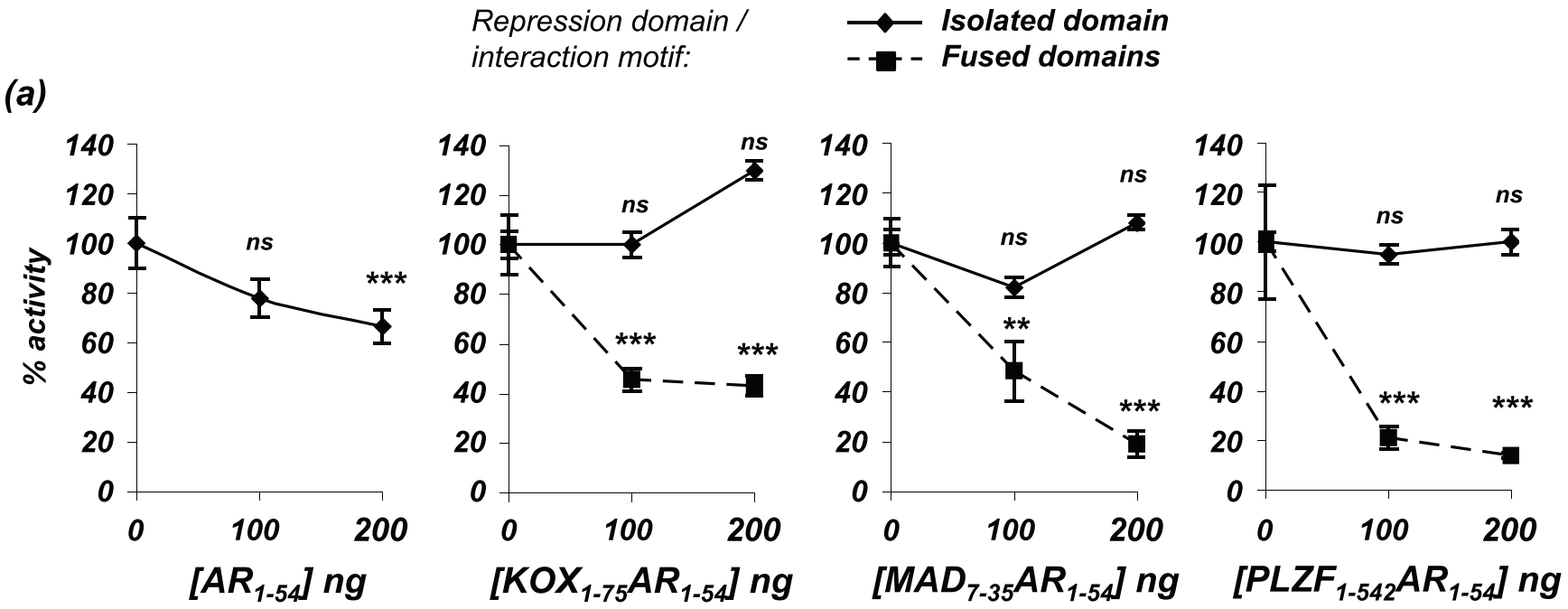

(b)
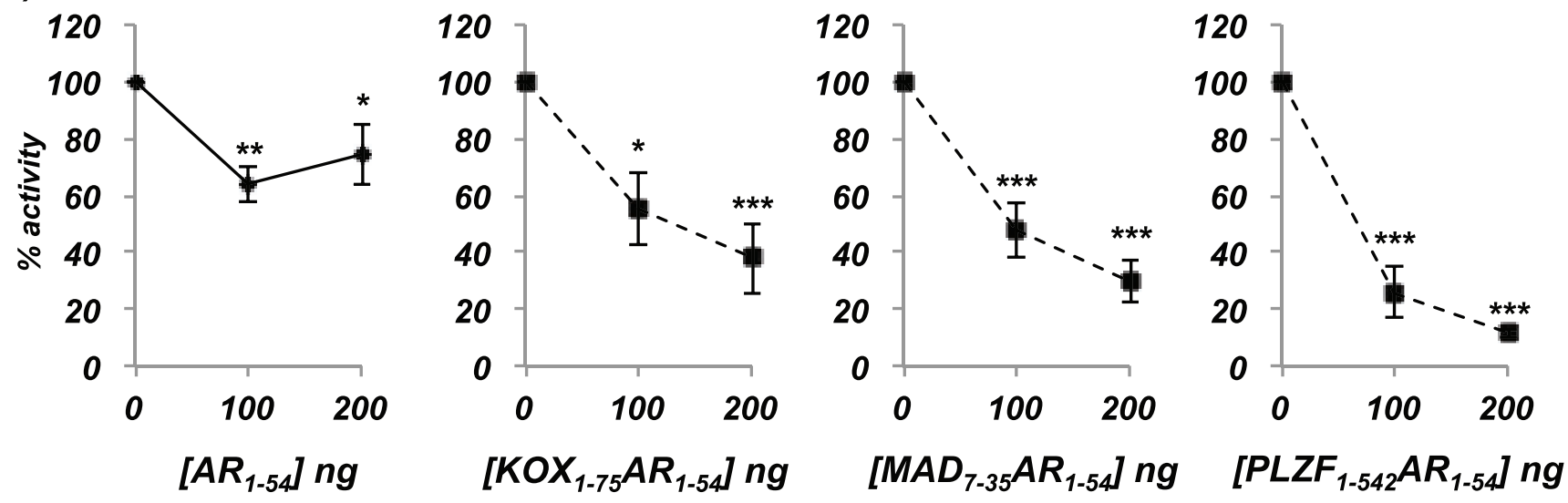

(c)

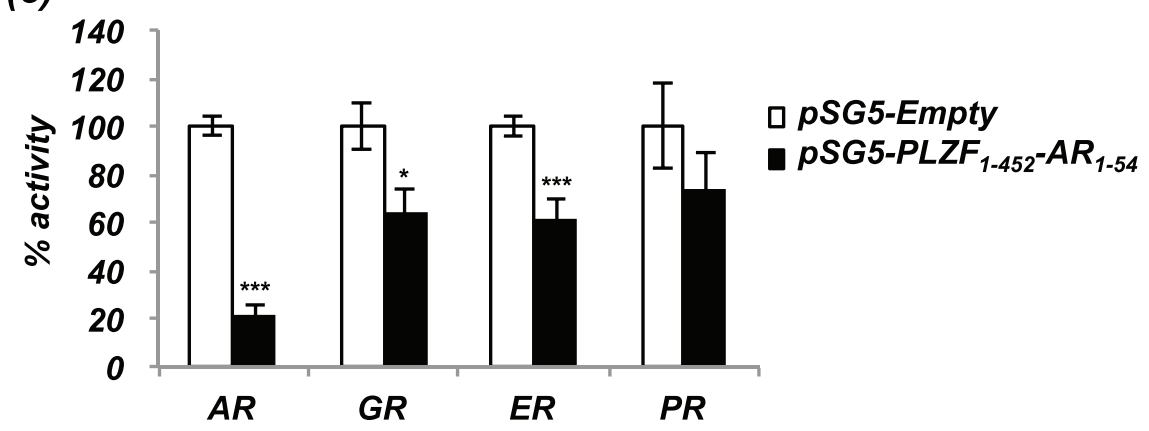

Figure 2: Inhibition of AR activity by the engineered repressors. (a) COS-1 cells were transiently transfected with vectors for the AR, TAT-GRE-E1B-LUC, PDM-LACZ- $\beta-G A L$ and the repressors or interaction motif either in isolation (solid line) or as a fusion (broken line). (b) PC3-WTAR were transiently transfected with vectors for TAT-GRE-E1B-LUC, PDM-LACZ- $\beta$-GAL, AR 1-54 $_{\text {or }}$ the repressors. (c) COS-1 cells were transfected with vectors encoding the androgen, glucocorticoid, oestrogen or progesterone receptors (AR, GR, ER, PR), the respective luciferase reporter construct (TAT-GRE-E1B-LUC or ERE-LUC), PDM-LACZ- $\beta$-GAL and PLZF ${ }_{1-452}-\mathrm{AR}_{1-54}$. Luciferase activity was normalised with $\beta$-galactosidase expression and results expressed as a $\%$ of AR activity in the absence of the repressors. Mean of 3 independent duplicates \pm 1 SE. T-Test - **p $<0.005, * * * p<0.0005$

other closely related steroid receptors (glucocorticoid, oestrogen and progesterone receptors) were also inhibited by the engineered repressors, transcription assays were performed using these receptors. COS-1 cells were therefore transfected with plasmids encoding $\mathrm{PLZF}_{1-452^{-}}$ $\mathrm{AR}_{1-54}$ and the steroid receptors, and cells treated with the corresponding ligand. The PLZF ${ }_{1-452}-\mathrm{AR}_{1-54}$ repressor weakly inhibited glucocorticoid, oestrogen 
and progesterone receptor activity by $<40 \%$ compared to approximately $80 \%$ inhibition of the AR (Figure $2 \mathrm{c}$ ).

To confirm that both the interaction domain and repression domain were required for inhibitory action, point mutations were introduced into these domains and activity measured using transcription assays. Mutation of the FQNLF interaction motif to FQNAA abolished repressive activity of $\mathrm{MAD}_{7-35}-\mathrm{AR}_{1-54}$ (Figure 3a). To confirm that the repression domain also contributes to repressive potential, mutations were introduced in to the repression motif of the $\mathrm{MAD}_{7-35} \mathrm{AR}_{1-54}$ vector. Mutation of residues L12 and A16 to prolines disrupted intrinsic transrepression activity (Supplementary Figure 1 and [24]). Fusion of the mutated $\mathrm{MAD}_{7-35}$ repression domain with $\mathrm{AR}_{1-54}$ generated a repressor with markedly weaker repressive activity compared to wild-type $\mathrm{MAD}_{7-35} \mathrm{AR}_{1-54}$ (Figure 3b). We therefore conclude that fusion of an interaction motif with a repression domain generates a potent repressor of AR activity and that both domains are essential for maximal inhibitory potential.
The engineered repressors successfully block Androgen Receptor activity in circumstances that promote hormone therapy failure

Much evidence exists to suggest that the AR can drive CRPC growth. One possible mechanism to explain therapy failure leading to CRPC is alterations in levels and/or activities of AR co-regulators sensitising the pathway to low levels or weakly androgenic ligands. Indeed, Gregory et al., demonstrated that the coactivators SRC1 (Steroid Receptor Coactivator 1) and TIF2 (transcriptional intermediary factor 2) were over-expressed in the majority of CRPCs [29], and altered expression and localisation of AR corepressors in prostate cancer has also been described (for example [30-34]). To determine whether the engineered repressors can inhibit AR activity enhanced by coactivator over-expression, COS1 cells were transfected with expression plasmids for the AR, SRC1 and increasing amounts of engineered repressor. SRC1 enhanced AR activity by 2.5 -fold and the LBD interaction (a)

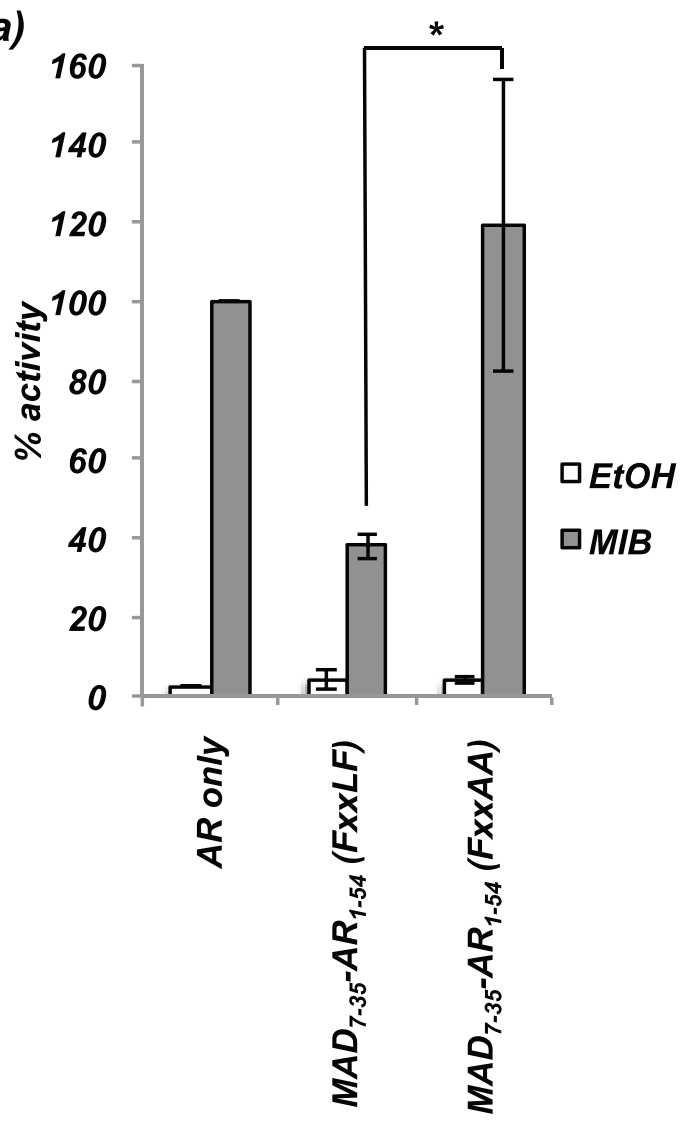

(b)

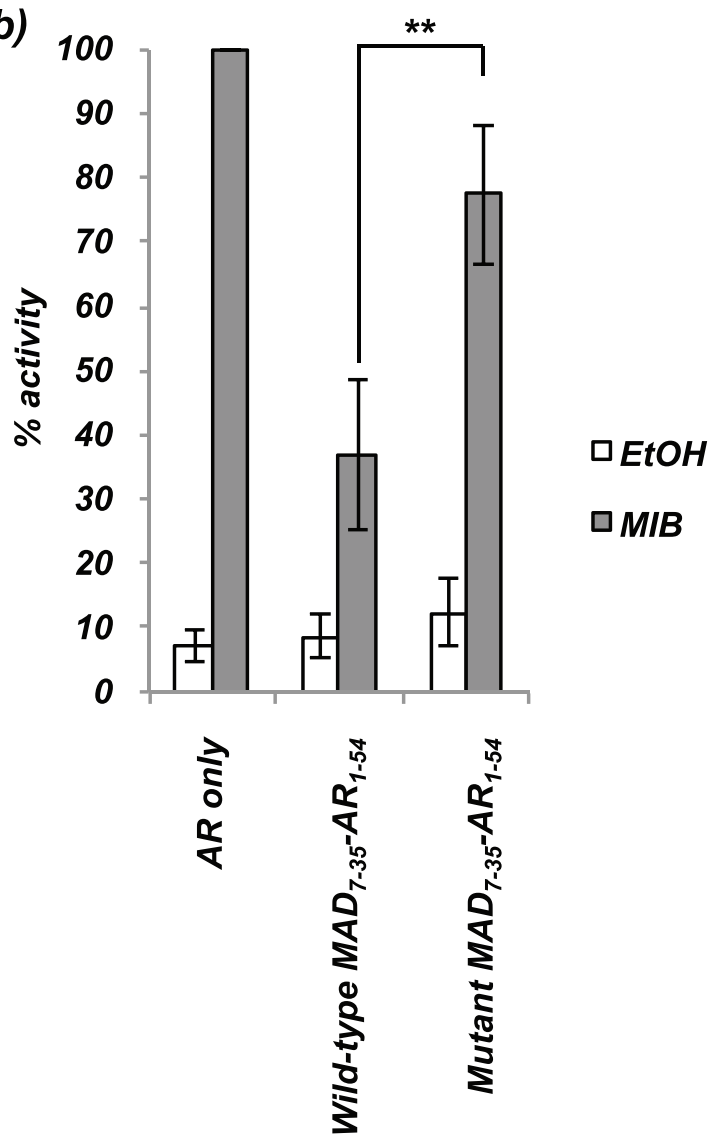

Figure 3: The repression domain and interaction motif are both essential for maximal repression of the AR. COS-1 cells were transiently transfected with vectors for the AR, TAT-GRE-E1B-LUC, PDM-LACZ- $\beta$-GAL and MAD 7-35 $^{-A_{1-54}}$ with wild-type or mutated (a) interaction motif (FQNLF to FQNAA) or (b) repression domain (L12P and A16P). Mean $\pm 1 \mathrm{SE}$. T-Test $-* * \mathrm{p}<0.005, * * *$ $\mathrm{p}<0.0005$. 
motif $\left(\mathrm{AR}_{1-54}\right)$ was unable to compete with this enhanced activity (Figure $4 \mathrm{a}$ ). By contrast, the engineered repressors were all able to significantly reduce the SRC1-enhanced AR activity (Figure 4b-d).

Mutations in the AR gene are rare in the early stages of prostate cancer, but their frequency increases significantly in advanced stages of the disease [35, 36]. For example, Gaddipati et al. found the T877A substitution in $25 \%$ of metastatic PCa samples analysed [37]. Some mutations appear to offer a growth advantage by reducing ligand specificity, allowing non-androgen ligands such as the antiandrogens cyproterone acetate (CPA) and hydroxyflutamide (OHF) to activate the receptor. To investigate if the engineered repressors can inhibit mutant ARs activated by these antiandrogens, COS-1 cells were transfected with two AR mutants commonly associated with prostate cancer (H874Y and T877A) and the engineered repressors. AR mutants H874Y and T877A were activated by mibolerone and to a lesser extent by CPA and OHF (Figure 5a and b). The engineered repressors were considerably more potent inhibitors of these AR mutants than $\mathrm{AR}_{1-54}$ for all ligand conditions.
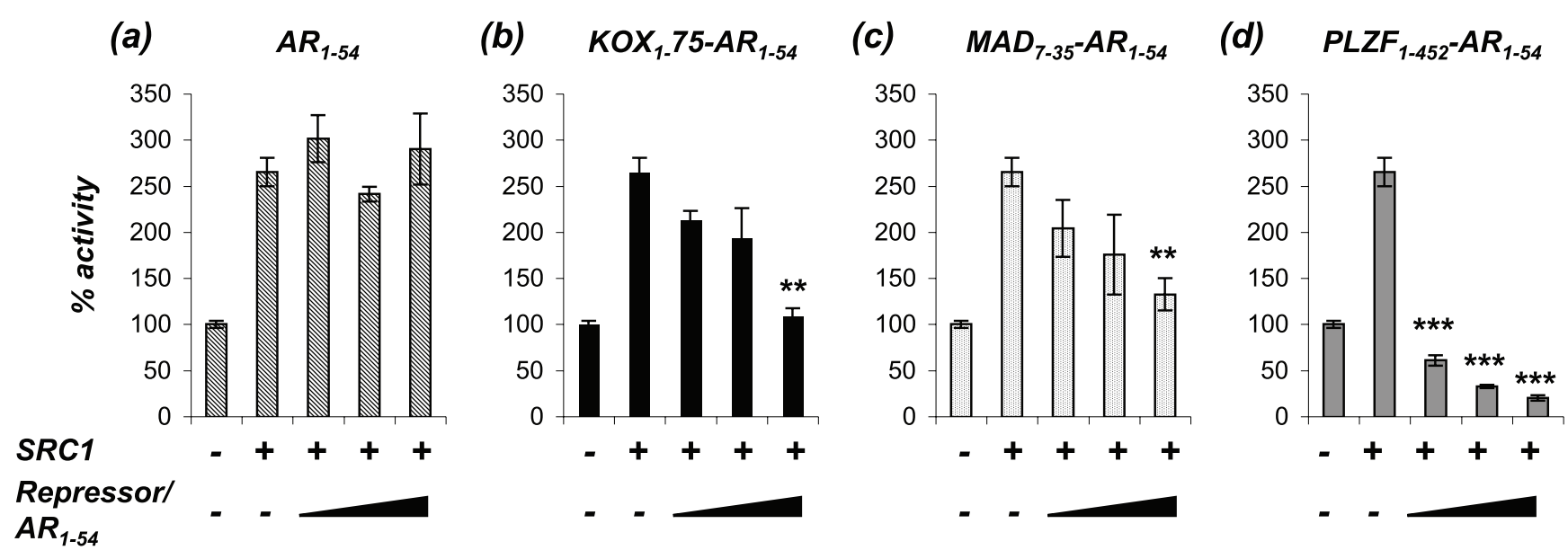

Figure 4: The repressors block AR activity enhanced by SRC1. COS-1 cells were transiently transfected with vectors for the AR, TAT-GRE-E1B-LUC, PDM-LACZ- $\beta-G A L, S R C 1$ and (a) $\mathrm{AR}_{1-54}$, (b) $\mathrm{KOX}_{1-75}-\mathrm{AR}_{1-54}$, (c) $\mathrm{MAD}_{7-35}-\mathrm{AR}_{1-54}$ or (d) $\mathrm{PLZF}_{1-542}-\mathrm{AR}_{1-54}$. Luciferase data was normalised to $\beta$-galactosidase expression and expressed as a $\%$ of AR activity in the absence of cofactor. Mean $\pm 1 \mathrm{SE}$. T-Test - ** $\mathrm{p}<0.005, * * * \mathrm{p}<0.0005$.

(a)

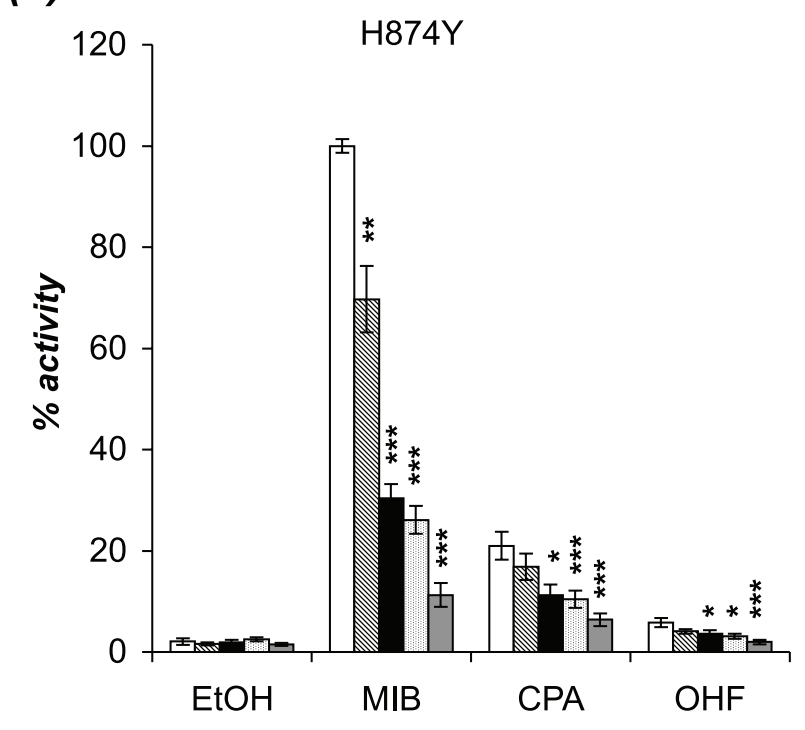

(b)

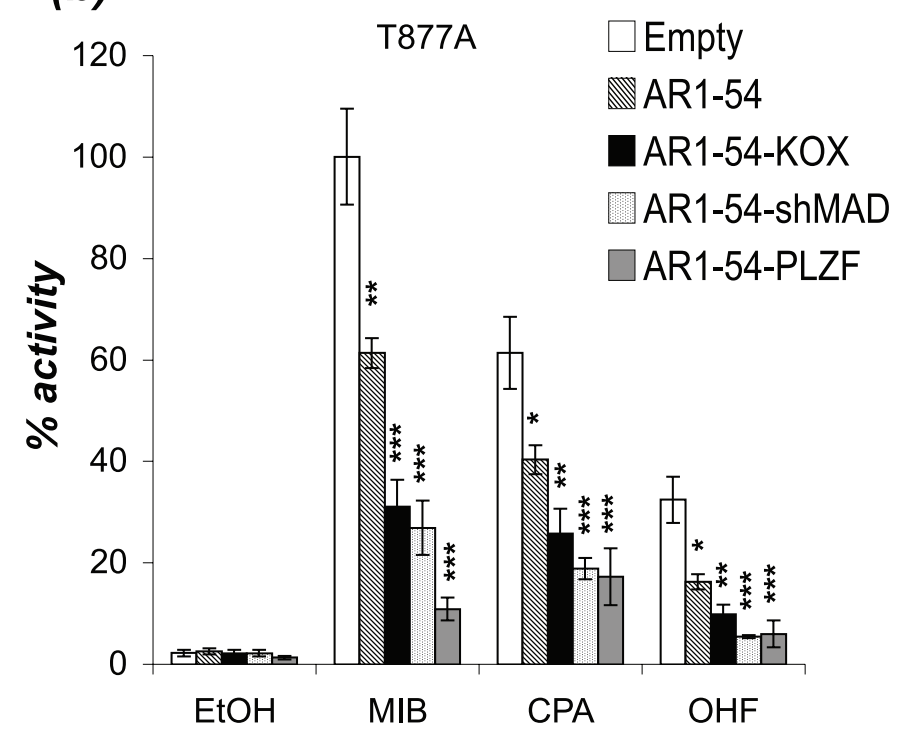

Figure 5: The engineered repressors block mutant ARs activated by androgen and antiandrogens. COS-1 cells were transiently transfected with vectors for the (a) H874Y or (b) T877A mutant ARs, TAT-GRE-E1B-LUC, PDM-LACZ- $\beta$-GAL and the repressors or interaction motif. EtOH - ethanol, MIB - mibolerone, CPA - cyproterone acetate, OHF - hydroxyflutamide. Mean \pm 1 SE. T-Test $* \mathrm{p}<0.05, * * \mathrm{p}<0.005, * * * \mathrm{p}<0.0005$. 


\section{The engineered repressors inhibit prostate cancer cell growth}

We have demonstrated that the engineered repressors are potent inhibitors of AR activity and inhibit receptor signalling in circumstances that would

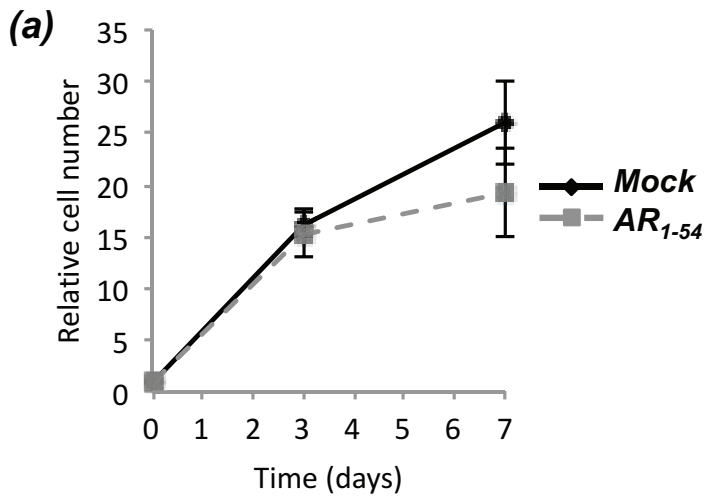

(c)

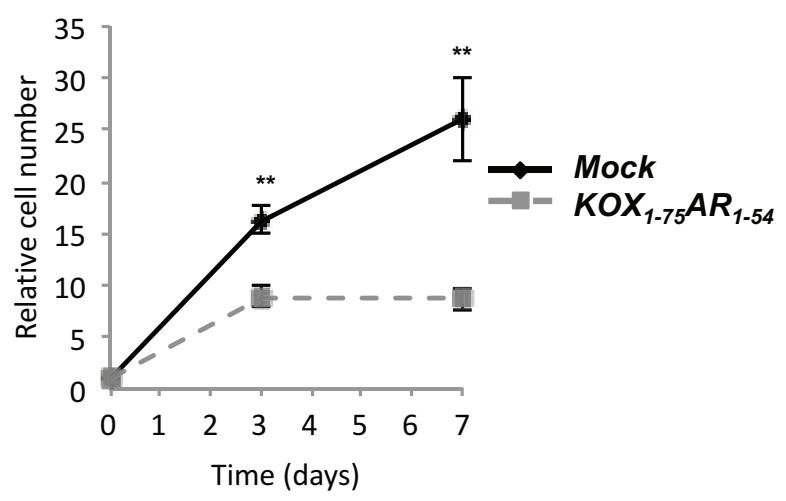

(e)

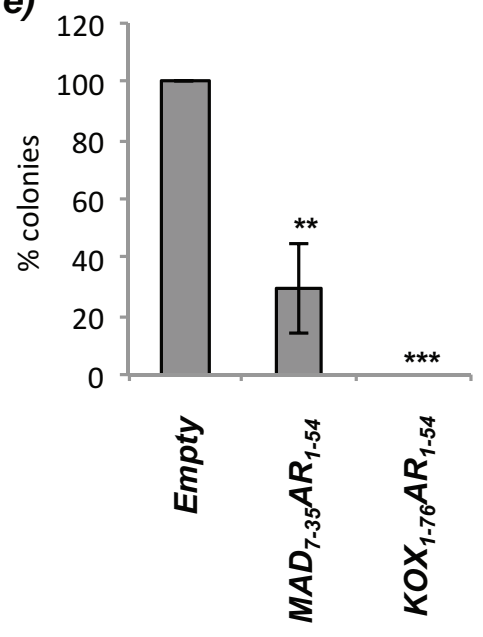

be predicted to promote CRPC. To determine whether these inhibitory effects translate into inhibition of prostate cancer growth, LNCaP cells were co-transfected with plasmids encoding GFP and the engineered repressors, and GFP positive cells counted over a time-course (Figure 6 and Supplementary Figure 2). $\mathrm{AR}_{1-54}$ had little effect upon

(b)

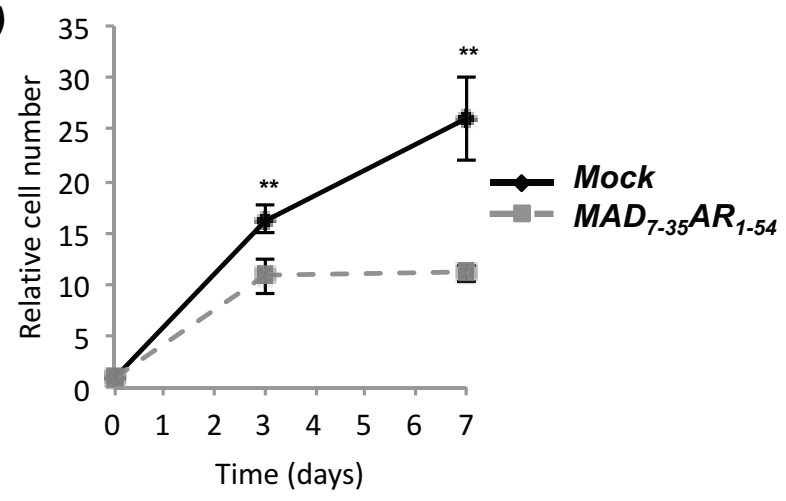

(d)

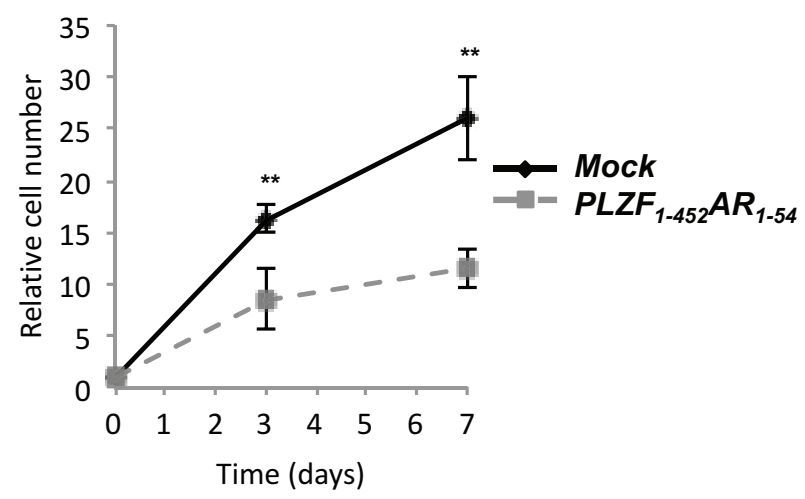

Figure 6: The engineered repressors significantly reduce prostate cancer proliferation. LNCaP cells were transiently co-transfected with vectors for GFP and (a) $\mathrm{AR}_{1-54}$, (b) $\mathrm{MAD}_{7-35} \mathrm{AR}_{1-54}$, (c) $\mathrm{KOX}_{1-75} \mathrm{AR}_{1-54}$ or (d) $\mathrm{PLZF}_{1-452} \mathrm{AR}_{1-54}$, GFP positive cells were counted $24 \mathrm{hrs}$ after transfection (set as day 0 ), and subsequently counted on days 3 and 7 . Automated counting (ImageJ) was performed on 10 random fields of view on an Axiovert Fluorescent Microscope (Zeiss), repeated in triplicate and representative figures given. (e) $\mathrm{LNCaP}-\mathrm{C} 42$ cells were transiently transfected with vectors encoding $\mathrm{MAD}_{7-35}-\mathrm{AR}_{1-54}, \mathrm{KOX}_{1-75}-\mathrm{AR}_{1-54}$ or Empty and the Zeocin selection cassette. Cells were selected with Zeocin for 3 weeks, colonies fixed, stained using crystal violet and colony number quantified. Mean \pm 1SE. T-Test * $<<0.05, * * \mathrm{p}<0.005, * * * \mathrm{p}<0.0005$. 
proliferation (Figure 6a), whereas the fusion constructs all significantly inhibited LNCaP growth within 3 days (Figure 6b-d). At day 7, $\mathrm{MAD}_{7-35}-\mathrm{AR}_{1-54}, \mathrm{KOX}_{1-75}-\mathrm{AR}_{1-54}$ and $\mathrm{PLZF}_{1-452}-\mathrm{AR}_{1-54}$ inhibited LNCaP growth by 67,57 and $55 \%$ respectively.

Colony formation assays were performed using the more aggressive LNCaP-C42 prostate cancer cell line [38] and the 2 shorter repressors $\left(\mathrm{MAD}_{7-35}-\mathrm{AR}_{1-54}, \mathrm{KOX}_{1-75}-\right.$ $\left.\mathrm{AR}_{1-54}\right)$. Exogenous expression of $\mathrm{MAD}_{7-35}-\mathrm{AR}_{1-54}$ and $\mathrm{KOX}_{1-75}-\mathrm{AR}_{1-54}$ significantly reduced colony formation, with no colonies emerging in any experiment using the latter construct (Figure 6E).

\section{DISCUSSION}

Hormone therapy targeting the AR pathway, is a common therapeutic option for the treatment of PCa. Although initially successful in the majority of patients, such therapies invariably fail after a median of 2 years and the tumours progress to the Castrate Resistant (CRPC) stage. Few therapeutic options exist for this stage of the disease, but much evidence exists to suggest that the AR continues to drive CRPC growth, and hence remains a valid therapeutic target [39].

Several groups have previously demonstrated that peptides designed to bind to regions important in AR activity (e.g. Activation Functions 1 and 2) can successfully inhibit AR activity [20-23]. We reasoned that fusing such peptides to repression domains derived from transcriptional repressor proteins would yield more potent inhibitors of AR activity. Therefore, we generated engineered repressors consisting of an AR LBD interaction motif $\left(\mathrm{AR}_{1-54}\right)$, fused to known repression domains from a number of potent transcriptional repressors, namely KOX, MAD and PLZF [24-26]). These are uniquely designed to interact with the AR when it is in an active conformation and subsequently block transcriptional activity. Reporter assays demonstrated that fusion of the repression domains to the $\mathrm{AR}_{1-54}$ interaction motif generated potent repressors of AR activity. Mutation of the interaction motif (FQNLF to FQNAA) completely abolished repression, whereas mutation of the $\mathrm{MAD}_{7-35}$ repression domain significantly reduced, but did not abolish inhibitory potential, likely as a result of the intact interaction motif since this alone possesses some inhibitory activity ([40] and data herein).

Upon ligand binding, steroid receptors interact with coactivators, which enhance transcriptional activity [8]. Despite high homology between the LBDs of steroid receptors, the AR is idiosyncratic in that it not only interacts with $\alpha$-helical LxxLL motifs present in coactivators such as SRC1 but also interacts with, and has preference for, similar phenylalanine rich motifs, e.g. FxxLF motifs, found in the coactivator ARA70 and in the N-terminus of the AR itself $[41,42]$. To provide AR selectivity of our repressors, we therefore utilised an N-terminal fragment of the $\operatorname{AR}\left(\mathrm{AR}_{1-54}\right)$ containing the ${ }^{23} \mathrm{FQNLF}^{27}$ motif that mediates the N-/C-terminal interaction [42]. The resulting $\mathrm{PLZF}_{1-452}-\mathrm{AR}_{1-54}$ repressor was found to be more specific for the AR but did also weakly inhibit the other steroid receptors. Previous studies using phenylalanine-rich motifs have also found weak cross-reactivity with these steroid receptors [21], hence refinement of such motifs warrants further investigation.

Multiple mechanisms have been described to explain therapy failure and CRPC, including alterations in AR cofactor levels/localisation. Transcriptional competition assays showed that, while the interaction motif alone was unable to compete with the effects of increased SRC1 expression, all of the engineered repressors were able to successfully inhibit AR activity under these conditions.

Mutation of the AR is another mechanism believed to contribute to CRPC [35]. Identified mutations in prostate cancer cluster in the LBD and several have been demonstrated to reduce ligand specificity. For example, the prostate cancer associated AR mutations H874Y and T877A can be activated by non-androgenic hormones (e.g. oestradiol and progesterone) and antiandrogens (e.g. CPA and $\mathrm{OHF}$ ) [11]. Importantly, the engineered repressors were able to reduce the activity of these mutants irrespective of the activating ligand, successfully blocking the receptors when activated by both androgen and anti-androgens.

We have therefore demonstrated that fusion of repression domains with an AR-specific interaction motif generates potent inhibitors of the AR that are more potent than interaction motifs alone, and that these constructs are active in circumstances where conventional therapeutics would be predicted to fail. Growth assays demonstrated that these repressive effects upon the AR do translate to growth inhibition of prostate cancer cells. Therefore, the use of engineered repressors is a potential therapeutic approach to inhibit CRPC, and methods to refine and deliver such constructs, for example viral delivery or nanoparticles, merit further investigation.

\section{METHODS}

\section{Ligands}

Mibolerone was purchased from Perkin Elmer (MA, USA). Oestradiol, Progesterone, Dexamethasone and Cyproterone Acetate were from Sigma Aldrich (MO, USA) and Bicalutamide and Hydroxyflutamide from Toronto Research Chemicals (Toronto, Canada).

\section{Constructs}

Amino acids 1-54 of the AR were PCR amplified and cloned into pSG5 using $\mathrm{XhoI}$ and BamHI. Repression domains from KOX (a.a. 1-75), MAD (a.a. 7-35) and PLZF (a.a. 1-452) were subsequently PCR cloned upstream of $\mathrm{AR}_{1-54}$ using EcoRI and XhoI. To generate the pCDNA4.0 (Invitrogen, Paisley, UK) engineered repressor constructs, 
the repressors were PCR cloned into the KpnI and $X b a \mathrm{I}$ sites. Site directed mutagenesis (QuickChange II, Agilent DE, USA) was performed on the pSG5-MAD ${ }_{7-35} \mathrm{AR}_{1-54}$ construct to generate constructs with mutation of the $\mathrm{AR}_{1-54}$ domain (FxxLF to FxxAA) or mutation of the repression domain (L12P and A16P). All constructs were confirmed by diagnostic digest and sequencing. The following plasmids have been previously described: pSG5SRC1e [43], pSVAR [44], TAT-GRE-EIB-LUC [45].

\section{Cell Culture}

COS1 and LNCaP cells were obtained from ATCC and grown at $37^{\circ} \mathrm{C} \quad 5 \% \quad \mathrm{CO}_{2}$. COS1 cells were grown in Dulbecco's modified Eagle's medium (DMEM) and LNCaP/LNCaP-C42 cells in Roswell Park Memorial Institute (RPMI) medium 1640 (Life technologies, Strathclyde, UK), both supplemented with $2 \mathrm{mM}$ L-Glutamine, 100units/ml penicillin, $100 \mathrm{mg} / \mathrm{ml}$ streptomycin (PSG) and 10\% foetal bovine serum. PC3WTAR cells [28] were grown as above with the addition of $4 \mu \mathrm{g} / \mathrm{ml}$ of Geneticin (Life Technologies, Gaithersburg, $\mathrm{MD})$. For experiments involving hormone manipulation, cells were cultured in phenol red free DMEM or RPMI supplemented with PSG and 5\% charcoal stripped foetal bovine serum (stripped medium).

\section{Confocal Microscopy}

COS 1 cells were plated at $30 \%$ confluence on cover slips in 24 well plates. Cells were transfected with pSVAR and pGFP-MAD ${ }_{7-35} \mathrm{AR}_{1-54}$ using FuGENE 6 (Promega, WI, USA) and incubated for $24 \mathrm{hrs}$ before treatment with ligand for $2 \mathrm{hrs}$. Wells were washed $3 \mathrm{x}$ with PBS and incubated in $1 \%$ paraformaldehyde for $10 \mathrm{~min}$, washed $3 \mathrm{x}$ in PBS and incubated for a further $10 \mathrm{~min}$ in $0.1 \%$ Triton $\mathrm{X}-100$ in PBS. Wells were again washed $3 \mathrm{x}$ with PBS, incubated in blocking solution (5\% BSA in PBS) for $30 \mathrm{~min}$ and a further $1 \mathrm{hr}$ with an AR antibody (AR C19, Santa Cruz Biotechnology, TX, USA) diluted 1:200 in blocking solution. Wells were washed $3 x$ with PBS, re-blocked and incubated for $1 \mathrm{hr}$ with 594-Alexa Fluor conjugated secondary antibody (Invitrogen, Paisley, UK). A final 3x PBS washes was performed before the coverslips were mounted onto glass slides (Vectorshield containing DAPI, DAKO, Cambridge, UK). Images were obtained using a Zeiss Confocal Microscope, as previously described [46].

\section{Immunoprecipitation}

COS1 cells were seeded at $70 \%$ confluence in $10 \mathrm{~cm}$ plates in 'stripped medium' and transfected with plasmids encoding the $\mathrm{AR}$ and GFP-MAD ${ }_{7-35} \mathrm{AR}_{1-54}$ using FuGENE 6.0 (Promega, WI, USA). Cells were left for $24 \mathrm{hrs}$, treated for $2 \mathrm{hrs} \pm 10 \mathrm{nM}$ Mibolerone and lysed in IP buffer (150mM NaCl, 1\% NP-40, 50mM Tris
pH8.0, 1mM DTT) containing freshly added protease inhibitors. Lysates were spun at 13,000 rpm (15 min, $4^{\circ} \mathrm{C}$ ), supernatants transferred to fresh tubes and protein concentration measured using the DC protein assay (BioRad, CA, USA). Lysates were pre-cleared with $50 \mu \mathrm{l}$ of sepharose beads (Sigma-Aldrich, MO, USA, 30min of rotation at $4^{\circ} \mathrm{C}$ ), supernatant transferred to fresh tubes and incubated with anti-GFP antibody (Abcam, Cambridge, UK) for $1 \mathrm{hr}$ with rotation before addition of $50 \mu \mathrm{l}$ of sepharose beads. After $1 \mathrm{hr}$, beads were washed 3 times with IP buffer, laemmli loading buffer added to the beads and samples boiled before protein separation using immunoblotting, as previously described [30].

\section{Reporter Assays}

COS1 cells were transfected using the calcium phosphate method as previously described [11]. Cells were seeded in 24 well plates and transfected per well with steroid receptor expression plasmids (100 ng), pDM-LACZ- $\beta$-GAL (100 ng), $1 \mu \mathrm{g}$ TAT-GRE-E1BLUC/ERE-LUC (1 $\mu \mathrm{g})$ and 0-200ng of pSG5-AR $1-54$, pSG5-MAD ${ }_{7-35}-\mathrm{AR}_{1-54}, \mathrm{KOX}_{1-75}-\mathrm{AR}_{1-54}, \mathrm{PLZF}_{1-452}-\mathrm{AR}_{1-54}$, pSG5-MAD ${ }_{7-35}-\mathrm{AR}_{1-54}$ (FQNAA)or pSG5-MAD ${ }_{7-35}$ (L12P, A16P)-AR ${ }_{1-54}$. PC3-WTAR cells were transfected with 50ng PDM-LACZ- $\beta$-GAL, 250ng TAT-GRE-E1B-LUC and $0-200 \mathrm{ng}$ of pSG5-AR ${ }_{1-54}, \mathrm{pSG} 5-\mathrm{MAD}_{7-35}-\mathrm{AR}_{1-54}$, $\mathrm{KOX}_{1-75}-\mathrm{AR}_{1-54}, \mathrm{PLZF}_{1-452}-\mathrm{AR}_{1-54}$ using FuGENE HD (Promega, WI, USA) following the manufacturer's instructions. Twenty-four hours after transfection, cells were treated with $10 \mathrm{nM}$ of ligand and cells incubated for a further $16 \mathrm{hrs}$. Luciferase and $\beta$-galactosidase expression was measured as previously described [11].

\section{Growth Assays}

LNCaP cells were plated to $50 \%$ confluence in 6 well plates in 'stripped media' containing $10 \mathrm{nM}$ Mibolerone and co-transfected with pGFP-Empty and plasmids encoding $\mathrm{AR}_{1-54}, \mathrm{MAD}_{7-35}-\mathrm{AR}_{1-54}, \mathrm{KOX}_{1-75}-\mathrm{AR}_{1-54}$ or PLZF $\mathrm{PL}_{1-452}-\mathrm{AR}_{1-54}$ using JetPrime (VWR International Ltd., Leicestershire, UK), following the manufacturers instructions. 24hrs after transfection (set as day 0), GFP positive cells were visualised in 10 random fields of view from triplicate wells using an Axiovert Fluorescent Microscope (Zeiss, x20 objective) and the number of GFP positive cells assessed using Image J (NIH). Subsequent cell counting was performed on days 3 and 7 .

\section{Colony Formation Assay}

Colony formation assays were based on Kawano et al. [47]. Briefly, LNCaP-C42 cells were plated in 6 well plates and transfected with $2 \mu \mathrm{g}$ of plasmid using JetPrime (VWR International Ltd., Leicestershire, UK). Twentyfour hours after transfection, cells were trypsinised and 
seeded in $10 \mathrm{~cm}$ dishes. RPMI media containing Zeocin $(300 \mu \mathrm{g} / \mathrm{ml}$, Invitrogen, Paisley, UK) was changed twice weekly and cells grown for 3 weeks, following which cells were washed in PBS, fixed and stained in $0.2 \%$ (w/v) crystal violet, $20 \% \mathrm{MeOH}$ (10min, RT). Plates were washed 6 times in $\mathrm{ddH}_{2} \mathrm{O}$ and cells counted manually.

\section{ACKNOWLEDGEMENTS}

We are grateful to all members of the Androgen Signalling Laboratory for continued advice and discussion. We are also thankful for financial support from Prostate Cancer UK, The Martin Harris Research Fellowship and the Johnson \& Johnson/Imperial Innovations Proof-ofConcept Fund.

\section{REFERENCES}

1. Robinson-Rechavi M, Escriva Garcia H and Laudet V. The nuclear receptor superfamily. J Cell Sci. 2003; 116(Pt 4):585-586.

2. Jenster G, van der Korput JA, Trapman J and Brinkmann AO. Functional domains of the human androgen receptor. J Steroid Biochem Mol Biol. 1992; 41(3-8):671-675.

3. Lonergan PE and Tindall DJ. Androgen receptor signaling in prostate cancer development and progression. J Carcinog. $2011 ; 10: 20$.

4. Langley E, Kemppainen JA and Wilson EM. Intermolecular NH2-/carboxyl-terminal interactions in androgen receptor dimerization revealed by mutations that cause androgen insensitivity. J Biol Chem. 1998; 273(1):92-101.

5. Callewaert L, Verrijdt G, Christiaens V, Haelens A and Claessens F. Dual function of an amino-terminal amphipatic helix in androgen receptor-mediated transactivation through specific and nonspecific response elements. J Biol Chem. 2003; 278(10):8212-8218.

6. He B, Lee LW, Minges JT and Wilson EM. Dependence of selective gene activation on the androgen receptor NH2- and COOH-terminal interaction. J Biol Chem. 2002; 277(28):25631-25639.

7. Heery DM, Kalkhoven E, Hoare S and Parker MG. A signature motif in transcriptional co-activators mediates binding to nuclear receptors. Nature. 1997; 387(6634): 733-736.

8. Bevan $\mathrm{C}$ and Parker $\mathrm{M}$. The role of coactivators in steroid hormone action. Exp Cell Res. 1999; 253(2):349-356.

9. Dubbink HJ, Hersmus R, Verma CS, van der Korput HA, Berrevoets CA, van Tol J, Ziel-van der Made AC, Brinkmann AO, Pike AC and Trapman J. Distinct recognition modes of FXXLF and LXXLL motifs by the androgen receptor. Mol Endocrinol. 2004; 18(9):2132-2150.

10. Estebanez-Perpina E, Moore JM, Mar E, DelgadoRodrigues E, Nguyen P, Baxter JD, Buehrer BM, Webb P, Fletterick RJ and Guy RK. The molecular mechanisms of coactivator utilization in ligand-dependent transactivation by the androgen receptor. J Biol Chem. 2005; 280(9):8060-8068.

11. Brooke GN, Parker MG and Bevan CL. Mechanisms of androgen receptor activation in advanced prostate cancer: differential co-activator recruitment and gene expression. Oncogene. 2008; 27(21):2941-2950.

12. Hur E, Pfaff SJ, Payne ES, Gron H, Buehrer BM and Fletterick RJ. Recognition and accommodation at the androgen receptor coactivator binding interface. PLoS Biol. 2004; 2(9):E274.

13. Hodgson MC, Shen HC, Hollenberg AN and Balk SP. Structural basis for nuclear receptor corepressor recruitment by antagonist-liganded androgen receptor. Mol Cancer Ther. 2008; 7(10):3187-3194.

14. Brzozowski AM, Pike AC, Dauter Z, Hubbard RE, Bonn T, Engstrom O, Ohman L, Greene GL, Gustafsson JA and Carlquist M. Molecular basis of agonism and antagonism in the oestrogen receptor. Nature. 1997; 389(6652):753-758.

15. Masiello D, Cheng S, Bubley GJ, Lu ML and Balk SP. Bicalutamide functions as an androgen receptor antagonist by assembly of a transcriptionally inactive receptor. J Biol Chem. 2002; 277(29):26321-26326.

16. Nagy L, Kao HY, Love JD, Li C, Banayo E, Gooch JT, Krishna V, Chatterjee K, Evans RM and Schwabe JW. Mechanism of corepressor binding and release from nuclear hormone receptors. Genes Dev. 1999; 13(24):3209-3216.

17. Whitaker HC, Hanrahan S, Totty N, Gamble SC, Waxman J, Cato AC, Hurst HC and Bevan CL. Androgen receptor is targeted to distinct subcellular compartments in response to different therapeutic antiandrogens. Clin Cancer Res. 2004; 10(21):7392-7401.

18. Saraon P, Jarvi K and Diamandis EP. Molecular alterations during progression of prostate cancer to androgen independence. Clin Chem. 2011; 57(10):1366-1375.

19. Zhang P, Zhang J, Young CY, Kao PC, Chen W, Jiang A, Zhang L and Guo Q. Decoy androgen-responsive element DNA can inhibit androgen receptor transactivation of the PSA promoter gene. Ann Clin Lab Sci. 2005; 35(3):278-284.

20. Minamiguchi K, Kawada M, Ohba S, Takamoto K and Ishizuka M. Ectopic expression of the amino-terminal peptide of androgen receptor leads to androgen receptor dysfunction and inhibition of androgen receptor-mediated prostate cancer growth. Mol Cell Endocrinol. 2004; 214(1-2):175-187.

21. van de Wijngaart DJ, Dubbink HJ, Molier M, de Vos C, Jenster $G$ and Trapman J. Inhibition of androgen receptor functions by gelsolin FxxFF peptide delivered by transfection, cell-penetrating peptides, and lentiviral infection. Prostate. 2011; 71(3):241-253.

22. Sadar MD. Small molecule inhibitors targeting the "achilles' heel" of androgen receptor activity. Cancer Res. 2011; 71(4):1208-1213.

23. Reeb CA, Gerlach C, Heinssmann M, Prade I, Ceraline J, 
Roediger J, Roell D and Baniahmad A. A designed cellpermeable aptamer-based corepressor peptide is highly specific for the androgen receptor and inhibits prostate cancer cell growth in a vector-free mode. Endocrinology. 2011; 152(6):2174-2183.

24. Ayer DE, Laherty CD, Lawrence QA, Armstrong AP and Eisenman RN. Mad proteins contain a dominant transcription repression domain. Mol Cell Biol. 1996; 16(10):5772-5781.

25. Margolin JF, Friedman JR, Meyer WK, Vissing H, Thiesen HJ and Rauscher FJ, 3rd. Kruppel-associated boxes are potent transcriptional repression domains. Proc Natl Acad Sci U S A. 1994; 91(10):4509-4513.

26. Pike J, Holmes D, Kamalati T, Davies D, Tolhurst R, Mazhar D, Fishpool S, al-Jehani R, Waxman J, Zelent A, Lemoine NR, Ali S and Buluwela L. Silencing of androgenregulated genes using a fusion of AR with the PLZF transcriptional repressor. Oncogene. 2004; 23(45):7561-7570.

27. He B, Kemppainen JA, Voegel JJ, Gronemeyer H and Wilson EM. Activation function 2 in the human androgen receptor ligand binding domain mediates interdomain communication with the $\mathrm{NH}(2)$-terminal domain. J Biol Chem. 1999; 274(52):37219-37225.

28. Peterziel H, Mink S, Schonert A, Becker M, Klocker H and Cato AC. Rapid signalling by androgen receptor in prostate cancer cells. Oncogene. 1999; 18(46):6322-6329.

29. Gregory CW, He B, Johnson RT, Ford OH, Mohler JL, French FS and Wilson EM. A mechanism for androgen receptor-mediated prostate cancer recurrence after androgen deprivation therapy. Cancer Res. 2001; 61(11):4315-4319.

30. Brooke GN, Culley RL, Dart DA, Mann DJ, Gaughan L, McCracken SR, Robson CN, Spencer-Dene B, Gamble SC, Powell SM, Wait R, Waxman J, Walker MM and Bevan CL. FUS/TLS is a novel mediator of androgen-dependent cell-cycle progression and prostate cancer growth. Cancer Res. 2011; 71(3):914-924.

31. Lavery DN, Villaronga MA, Walker MM, Patel A, Belandia B and Bevan CL. Repression of androgen receptor activity by HEYL, a third member of the Hairy/Enhancerof-split-related family of Notch effectors. J Biol Chem. 2011; 286(20):17796-17808.

32. Belandia B, Powell SM, Garcia-Pedrero JM, Walker MM, Bevan CL and Parker MG. Hey1, a mediator of notch signaling, is an androgen receptor corepressor. Mol Cell Biol. 2005; 25(4):1425-1436.

33. Elmore LW, Forsythe R, Forsythe H, Bright AT, Nasim S, Endo $\mathrm{K}$ and Holt SE. Overexpression of telomeraseassociated chaperone proteins in prostatic intraepithelial neoplasia and carcinomas. Oncol Rep. 2008; 20(3):613-617.

34. Hu YC, Yeh S, Yeh SD, Sampson ER, Huang J, Li P, Hsu CL, Ting HJ, Lin HK, Wang L, Kim E, Ni J and Chang C. Functional domain and motif analyses of androgen receptor coregulator ARA70 and its differential expression in prostate cancer. J Biol Chem. 2004; 279(32):33438-33446.

35. Brooke GN and Bevan CL. The role of androgen receptor mutations in prostate cancer progression. Curr Genomics. 2009; 10(1):18-25.

36. Brooke GN and Bevan CL. The role of androgen receptor mutations in prostate cancer progression. Curr Genomics. 2009; 10(1):18-25.

37. Gaddipati JP, McLeod DG, Heidenberg HB, Sesterhenn IA, Finger MJ, Moul JW and Srivastava S. Frequent detection of codon 877 mutation in the androgen receptor gene in advanced prostate cancers. Cancer Res. 1994; 54(11): 2861-2864.

38. Wu HC, Hsieh JT, Gleave ME, Brown NM, Pathak S and Chung LW. Derivation of androgen-independent human LNCaP prostatic cancer cell sublines: role of bone stromal cells. Int J Cancer. 1994; 57(3):406-412.

39. Tsao CK, Galsky MD, Small AC, Yee T and Oh WK. Targeting the androgen receptor signalling axis in castration-resistant prostate cancer (CRPC). BJU Int. 2012; 110(11):1580-1588.

40. Minamiguchi K, Kawada M, Ohba S, Takamoto K and Ishizuka M. Ectopic expression of the amino-terminal peptide of androgen receptor leads to androgen receptor dysfunction and inhibition of androgen receptor-mediated prostate cancer growth. Mol Cell Endocrinol. 2004; 214(1-2):175-187.

41. He B and Wilson EM. Electrostatic modulation in steroid receptor recruitment of LXXLL and FXXLF motifs. Mol Cell Biol. 2003; 23(6):2135-2150.

42. He B and Wilson EM. The NH(2)-terminal and carboxylterminal interaction in the human androgen receptor. Mol Genet Metab. 2002; 75(4):293-298.

43. Kalkhoven E, Valentine JE, Heery DM and Parker MG. Isoforms of steroid receptor co-activator 1 differ in their ability to potentiate transcription by the oestrogen receptor. EMBO J. 1998; 17(1):232-243.

44. Brinkmann AO, Faber PW, van Rooij HC, Kuiper GG, Ris C, Klaassen P, van der Korput JA, Voorhorst MM, van Laar JH, Mulder E and et al. The human androgen receptor: domain structure, genomic organization and regulation of expression. J Steroid Biochem. 1989; 34(1-6):307-310.

45. Jenster G, van der Korput HA, van Vroonhoven C, van der Kwast TH, Trapman J and Brinkmann AO. Domains of the human androgen receptor involved in steroid binding, transcriptional activation, and subcellular localization. Mol Endocrinol. 1991; 5(10):1396-1404.

46. Whitaker HC, Hanrahan S, Totty N, Gamble SC, Waxman $\mathrm{J}$, Cato AC, Hurst HC and Bevan CL. Androgen receptor is targeted to distinct subcellular compartments in response to different therapeutic antiandrogens. Clin Cancer Res. 2004; 10(21):7392-7401.

47. Kawano Y, Diez S, Uysal-Onganer P, Darrington RS, Waxman J and Kypta RM. Secreted Frizzled-related protein-1 is a negative regulator of androgen receptor activity in prostate cancer. Br J Cancer. 2009; 100(7):1165-1174. 